https://doi.org/10.25208/0042-4609-2019-95-3-10-15

Собенности пигментации себорейного кератоза

Александрова А. К. ${ }^{*}$ Смольянникова В. А.

Первый Московский государственный медицинский университет им. И. М. Сеченова (Сеченовский университет) Министерства здравоохранения Российской Федерации

119991, Российская Федерация, г. Москва, ул. Трубецкая, д. 8, стр. 2

Себорейный кератоз (СК) - распространенная доброкачественная эпителиальная опухоль кожи, существующая во множестве клинических вариантов. Цвет опухоли варьирует от светло-желтого до темно-коричневого, что часто приводит к диагностическим ошибкам. Работы, посвященные пигментации СК, единичны. Нет единого мнения о содержании меланоцитов в СК.

Цель исследования: изучить характер распределения меланина в СК и его взаимосвязь с количеством меланоцитов.

Материалы и методы. Проведен анализ 130 гистологических препаратов с верифицированным диагнозом СК, ииммуногистохимическое (ИГХ) исследование с моноклональными антителами k Melan A (clone A103 ready-to-use). Взятие материала проводили у 130 пациентов с CK в возрасте 46-77 лет: в 48,5 \% с мест, которые легко подвергаются воздействию солнечного света, в 51,5 \% с мест, чаще закрытых, менее склонных к облучению УФ-лучами.

Результаты. В результате гистологического исследования были выделены три типа пигментации СК в зависимости от накопления и расположения пигмента в опухоли. ИГХ-исследование с моноклональными антителами к Melan А выявило достоверное снижение количества меланоцитов в СК (0,7-5 \%) по сравнению с прилежащим к опухоли неизмененным эпидермисом (10,7-14,3 \%) ( $p=0,001)$. Наибольшее количество меланоцитов (3-5 \%) регистрировалось в наименее пигментированных СК, удаленных с мест, подверженных УФ-излучению.

Выводы. Значительное снижение содержания меланоцитов (менее 3 \% клеток опухоли) в наиболее пигментированных СK ( $p=0,0003)$, отсутствие активации меланогенеза в опухоли под воздействием УФ-излучения свидетельствует о накоплении пигмента в связи с его замедленной утилизацией из-за старения и снижения метаболизма клеток опухоли.

Ключевые слова: сөборөйный көратоз, пигментация, Mөlan A

Конфрликт интересов: авторы заявляют об отсутствии потенциального конфликта интересов, требующего раскрытия в данной статье.

Для цитирования: Александрова А. К., Смольянникова В. А. Особенности пигментации себорейного кератоза. Вестник дерматологии и венерологии. 2019;95(3):10-15. https://doi.org/10.25208/0042-4609-2019-95-3-10-15 


\title{
On the peculiarities of seborrheic keratosis pigmentation
}

\author{
Alexandra K. Alexandrova*, Vera A. Smolyannikova
}

I. M. Sechenov First Moscow State Medical University, Ministry of Health of the Russian Federation

Trubetskaya str., 8, bldg 2, Moscow, 119991, Russian Federation

Seborrheic keratosis (SK) is a common benign epithelial skin tumor that exists in a variety of clinical options. The color of the tumor varies from yellow to dark brown, which leads to diagnostic errors. There is alittle data about pigmentation of the SK in the literature. There is no consensus on the content of melanocytes in the SK.

Objective: to study the nature of the distribution of melanin in the SK and its relationship with the number of melanocytes.

Materials and methods. An analysis of 130 histological preparations with a verified diagnosis of SK and immunohistochemistry (IHC) test with monoclonal antibodies to Melan A (clone A103 ready-to-use) have been performed. Material sampling was performed in 130 patients with SK at the age of $46-77$. In $48.5 \%$ of the material was taken from places that are easily exposed to sunlight, $51.5 \%$ from places that are often closed, less prone to exposure to UV-radiation.

Results. As a result of histological examination, three types of pigmentation of the SK were identified, depending on the accumulation and location of pigment in the tumor. IHC test with monoclonal antibodies to Melan A in all cases of SK revealed a significant decrease in the content of melanocytes (0.7-5\%), compared with the unaffected epidermis $(10.7-14.3 \%)(p=0.001)$. The greatest number of melanocytes $(3-5 \%)$ was recorded in SK, which were removed from places exposed to UV radiation.

Conclusions. A significant decrease in the content of melanocytes (less than $3 \%$ of tumor cells) in the most pigmented SK $(p=0.0003)$, the lack of activation of melanogenesis in the tumor under the influence of UV radiation indicates the accumulation of pigment due to its slow utilization, due to aging and a decrease in metabolismtumor cells.

\section{Keywords: seborrheic keratosis, pigmentation, Melan A}

Conflict of interest: the authors state that there is no potential conflict of interest requiring disclosure in this article.

For citation: Alexandrova A. K., Smolyannikova V. A. On the peculiarities of seborrheic keratosis pigmentation. Vestnik Dermatologii i Venerologii. 2019;95(3):10-15. https://doi.org/10.25208/0042-4609-2019-95-3-10-15 
Себорейный кератоз (СК) - наиболее распространенная доброкачественная эпителиальная опухоль кожи, существующая во множестве клинических вариантов. Проявляется заболевание на ранней стадии пятнами желто-коричневой окраски, которые постепенно превращаются в выпуклые бляшки, как будто «приклеенные» к коже. Они мягкой консистенции, с гладкой или веррукозной поверхностью, с сальным блеском. Часто видны множественные роговые кисты в виде темных точек в центре СК. Диаметр образований варьирует от нескольких мм до нескольких см. СК может быть грязно-желтого, светло-коричневого или темного, почти черного цвета, часто имитируя другие как доброкачественные, так и злокачественные новообразования кожи. При гистологическом исследовании выявляется в разной степени выраженности гиперкератоз, акантоз, папилломатоз, а также истинные роговые и псевдороговые кисты. В СК присутствуют три основных вида клеток: базалоидные кератиноциты, шиповатые клетки и меланоциты [1, 2]. При СК пигментация практически не изучена. В литературе имеются лишь сведения о повышенном в более половине изучаемых случаев количестве меланина в СК по сравнению с нормальным эпидермисом, основанные на анализе препаратов, окрашенных гематоксилином и эозином и по методу Массона - Фонтаны [3]. Однако наиболее важным маркером меланоцитов в последнее время признан MelanA (MART-1) - трансмембранный протеин, продукт гена MLANA. Он присутствует в меланосомах меланоцитов кожи, сетчатки, мозговых оболочек и улитке уха [1]. Многими авторами Melan A рассматривается в качестве диагностического маркера меланомы и доброкачественных пигментированных эпителиальных опухолей кожи $[4,5]$.

Исследований по изучению содержания меланоцитов в СK, в частности с использованием Melan A (MART-1) - антигена диффреренцировки меланоцитов, не проводилось.

Цель: изучить характер распределения меланина в СК и его взаимосвязь с количеством меланоцитов.

\section{Материалы и методы}

Материалом для гистологического исследования послужил операционный материал опухолей кожи от 130 пациентов с СК: 83 (63,8 \%) женщин и 47 (36,2\%) мужчин в возрасте от 46 до 77 лет (средний возраст составил 63,6 года). Хирургическим путем под местной анестезией 0,5 \% раствором новокаина иссекалась вся опухоль в пределах здоровых тканей, отступя от ее края не менее чем 0,5 cм. Операционное вмешательство проводилось с письменного информированного согласия пациентов. Для иссечения выбирался элемент СК В виде плоского, умеренно пигментированного очага овальной формы, не более 2 см в диаметре, с гиперкератотической поверхностью.

В 48,5 \% (63 СК) взятие материала проводилось с мест, которые легко подвергаются воздействию солнечного света: с кожи лица, шеи, области декольте, плеч; в 51,5 \% (67CK) - с мест, чаще закрытых, менее склонных к облучению УФ-лучами: с кожи живота, нижней трети спины и боковых поверхностей туловища. Материал обрабатывали по стандартной методике, с заливкой в парафиновые блоки, из которых готовили гистологические препараты с окраской гематоксили- ном и эозином. Иммуногистохимическое (ИГХ) исследование проводили стрептавидин-биотин-пероксидазным методом по общепринятой схеме на парафиновых срезах толщиной 5 мкм. Использовались мышиные моноклональные антитела к Melan A (clone A103 ready-touse, Novocastra Ltd). В качестве контроля использовали рекомендованные производителями ткани. Результаты ИГХ-исследования оценивали по количеству положительно окрашенных клеток опухоли к 300 клеткам опухоли в местах с наибольшей экспрессией.

Статистическая обработка материала проведена с использованием статистического пакета программ Statisticafor Windows v.10 и SPSS v21. Для сравнения качественных параметров применяли точный критерий Фишера. Различия считали значимыми при $p<0,05$ (95\% точности). Степень взаимосвязи параметров оценивали с помощью корреляционного анализа по Спирмену.

\section{Результаты и обсуждение}

При анализе 130 гистологических препаратов распределение пигмента меланина в СК носило неравномерный, часто очаговый характер. Так, в серийных срезах СК в центральных отделах можно было встретить усиленное отложение пигмента над апикальными полюсами ядер в клетках опухоли, а в краевых - его почти полное отсутствие. Клинически присутствие в одной СК очагов с разным типом пигментации проявлялось неравномерной окраской опухоли (рис. 1).

Мы выделили три основных типа пигментации СК.

I тип. Слабая пигментация отдельных клеток опухоли, преимущественно в области дермоэпидермальной границы или отдельными очагами. Меланин располагался в виде «шапочек» над апикальными полюсами ядер клеток и/или в виде единичных отдельных глыбок и меланофрагов в дерме и строме опухоли - в 83 СK (63,8 \%) (рис. 2).

II тип. Равномерная пигментация клеток, расположенных на дермоэпидермальной границе, с единичными меланофагами в дерме и строме опухоли или их полным отсутствием - в 31 CK (23,9 \%). 
Таблица 1. Характер пигментации СК в зависимости от места локализации опухоли

Table 1. Character of SK pigmentation depending on the tumour localisation

\begin{tabular}{|c|c|c|c|c|c|}
\hline & & \multicolumn{4}{|c|}{ Локализация СK } \\
\hline \multicolumn{2}{|c|}{ Тип пигментации } & \multicolumn{2}{|c|}{ без УФ } & \multicolumn{2}{|c|}{ УФ-излучение } \\
\hline & & абс. & $\%$ & абс. & $\%$ \\
\hline \multirow{3}{*}{ Всего } & 1 & 96 & 50,2 & 80 & $73,4^{*}$ \\
\hline & ॥ & 54 & 28,3 & 25 & 22,9 \\
\hline & III & 41 & 21,5 & 4 & $3,7^{*}$ \\
\hline
\end{tabular}

Примечание: * - достоверные различия по сравнению с группой без УФ ( $p=0,0001, p=0,00001)$. Note: ${ }^{*}$ — statistically significant differences compared to a group without UV $(p=0.0001, p=0.00001)$.

III тип. Выраженная дифффузная пигментация в виде большого количества меланина в клетках, расположенных в основании опухоли и вышележащих слоях, скопления меланина в виде глыбок и меланофрагов в дерме и строме опухоли - в 16 CK (12,3\%).

На характер пигментации в опухоли влияло УФ-излучение, и, в отличие от неизмененного эпидермиса, это была отрицательная взаимосвязь. Так, в СК, удаленных с подверженных УФ-излучению мест, достоверно чаще встречался I тип пигментации (73,4\%), тогда как III тип пигментации - только в 3,7 \% CK $(p=0,0001)$ (табл. 1). Это подтверждают и клинические наблюдения: большинство наиболее пигментированных СК находились у пациентов на коже живота и нижней трети спины.

Меланоциты в СК, по данным экспрессии моноклональных антител к MelanA, располагались неравномерно, преимущественно в клетках, расположенных на дермоэпидермальной границе (рис. 3), значительно реже - в центральных отделах СК и составляли всего 2-15 (0,7-5 \%) клеток опухоли, что достоверно $(p=0,001)$ отличалось от неизмененного эпидермиса, в котором положительная реакция регистрировалась в 32-43 (10,7-14,3 \%) клетках (табл. 2). Как и в здоровой коже [1, 3], наибольшее количество меланоцитов встречалось в СК, подверженных УФ-излучению. В них В $68,2 \%$ регистрировалась положительная реакция

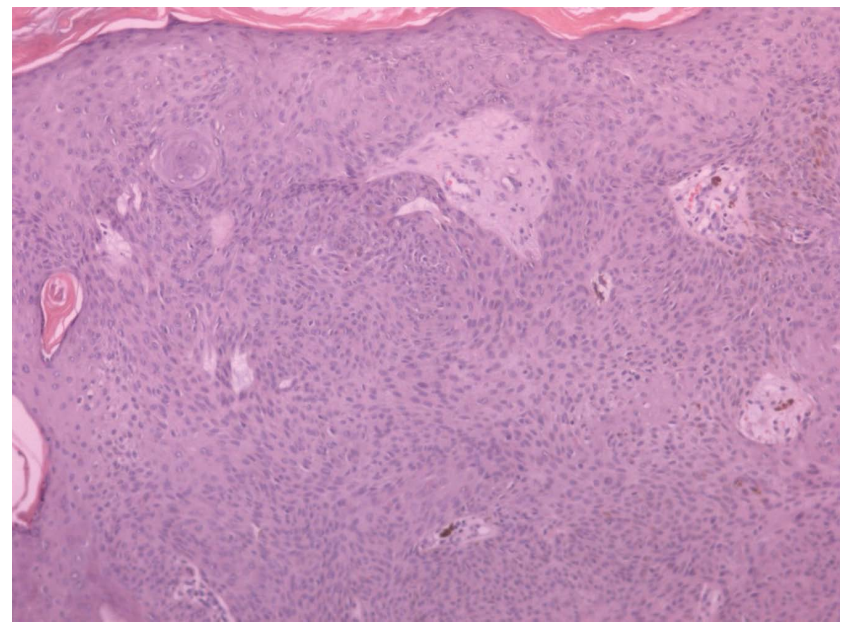

Рис. 2. Себорейная кератома. I тип пигментации. Гематоксилин и эозин, $\times 200$

Fig. 2. Seborrheic keratosis. Type I pigmentation. Hematoxylin and eosin, $\times 200$
Таблица 2. Экспрессия моноклональных антител к MelanA в СК и неизмененном эпидермисе

Table 2. Expression of monoclonal antibodies to MelanA in SK and unchanged epidermis

\begin{tabular}{cc}
\hline Melan A, количество клеток & Всего \\
\hline CK $(n=130)$ & $2-15(6,2 \pm 3,6)$ \\
\hline Неизмененный эпидермис $(n=130)$ & $32-43(37,8 \pm 6,0)^{*}$
\end{tabular}

Примечание: * — достоверные различия с СK $(p=0,001)$. Note: * — statistically significant differences for SK $(p=0.001)$.

в 3-5 \% клеток, тогда как на закрытых от солнечного излучения участках ни в одном случае количество положительно окрашенных клеток не превышало 3 \%. Вызывает интерес и фракт отрицательной взаимосвязи содержания меланоцитов в опухоли с характером пигментации. Наибольшее количество меланоцитов (3-5 \%) достоверно чаще регистрировалось в слабопигментированных СK (43,3\%) ( $p=0,003)$, тогда как в наиболее пигментированных опухолях (III тип пигментации) количество меланоцитов не превышало 3 \% ни в одном случае (табл. 3).

Важно учитывать тот факт, что главной в этиологии CK является теория «старения» кертиноцитов, а на выживание меланоцитов, их дендритность, меланогенез

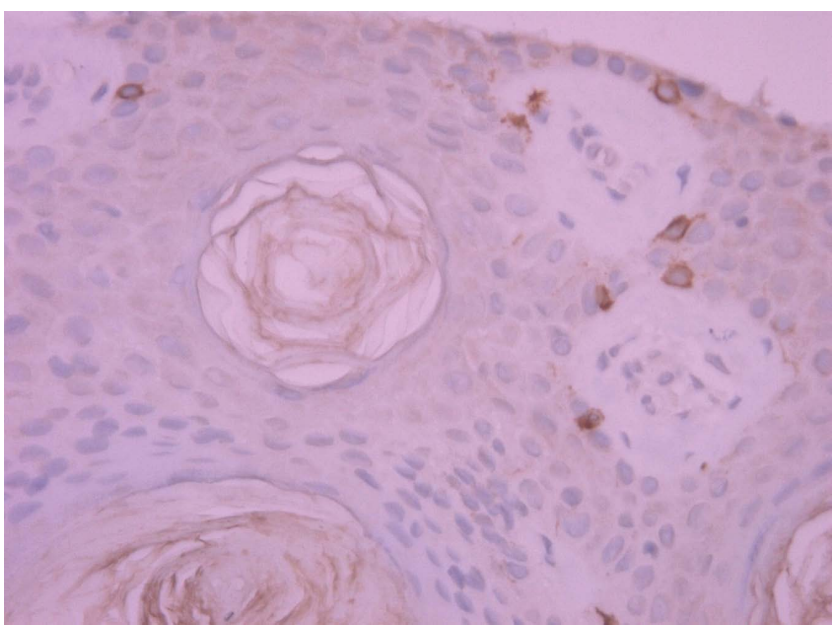

Рис. 3. Экспрессия моноклональных антител к MelanA в себорейной кератоме. Иммунопероксидазный метод, ×400

Fig. 3. Expression of monoclonal antibodies to MelanA under seborrheic keratosis. Immunoperoxidase method, $\times 400$ 
Таблица 3. Взаимосвязь характера пигментации и экспрессии моноклональных антител к Melan A в СK

Table 3. Correlation between the character of pigmentation and expression of monoclonal antibodies to MelanA in SK

\begin{tabular}{|c|c|c|c|c|c|c|c|}
\hline & & \multicolumn{6}{|c|}{ Тип пигментации } \\
\hline \multicolumn{2}{|c|}{ Melan A } & \multicolumn{2}{|c|}{ I } & \multicolumn{2}{|c|}{$\|$} & \multicolumn{2}{|c|}{ III } \\
\hline & & абс. & $\%$ & абс. & $\%$ & абс. & $\%$ \\
\hline \multirow{2}{*}{ Всего } & до $3 \%$ & 47 & 56,6 & 24 & $77,4^{*}$ & 16 & $100,0^{*+}$ \\
\hline & $3-5 \%$ & 36 & 43,4 & 7 & 22,6 & 0 & 0,0 \\
\hline Melan A & $\begin{array}{c}\text { количество } \\
\text { клеток }\end{array}$ & \multicolumn{2}{|c|}{$6,9 \pm 3,8$} & \multicolumn{2}{|c|}{$5,4 \pm 3,1$} & \multicolumn{2}{|c|}{$4,3 \pm 2,0^{*}$} \\
\hline
\end{tabular}

Примечание: * — достоверные различия с I типом пигментации, $p=0,032, p=0,0003 ;{ }^{+}$— достоверные различия с II типом пигментации, ${ }^{+} p=0,042 ;$ среднее количество клеток, ${ }^{*} p=0,009$.

Note: * - statistically significant differences for type I pigmentation, $p=0.032, p=0.0003 ;{ }^{+}$- statistically significant differences for type II pigmentation, ${ }^{+} p=0.042 ;$ average number of cells ${ }^{*} p=0.009$.

и экспрессию рецепторов на клеточной поверхности значительное влияние оказывают сигналы от клеток опухоли, как и в эпидермисе - от кератиноцитов, где большинство сигналов индуцируется УФ-излучением [1]. Однако в СК, в отличие от неизмененного эпидермиса, стимуляции меланогенеза при воздействии УФ-излучения не происходило. Таким образом, наиболее вероятной причиной накопления значительного количества пигмента, причем неравномерно распределенного в опухоли, при почти полном отсутствии меланоцитов, является его накопление, а не увеличение синтеза, в результате «старения» клеток СК и снижения их фрункциональной активности, что приводит к нарушениям эпидермального баланса между стимуляторами и ингибиторами меланогенеза - паракринными цитокинами. Об этом свидетельствуют и данные литературы об излишней экспрессии в СК фрактора некроза опухоли-а и других провоспалительных цитокинов, ингибиторов меланогенеза в сочетании с повышенным содержанием эндотелина 1 - известного митогена для меланоцитов и стимулятора меланогенеза [6]. Таким образом, характер пигментации являлся своеобразным показателем «возраста» кератомы, отражающим степень выраженности нарушений в процессах терминальной дифференцировки.

\section{Выводы}

Выявленное в исследовании значительное снижение содержания меланоцитов в наиболее пигментированных СК, отсутствие активации меланогенеза в опухоли под воздействием УФ-излучения свидетельствует о накоплении пигмента в связи с его замедленной утилизацией из-за старения и снижения метаболизма клеток опухоли. Этим объясняется наличие в СК очагов с разным типом пигментации, что клинически проявляется неравномерностью окраски.

\section{Участие авторов:}

Концепция и дизайн исследования - Александрова А. К, Смольянникова В. А.

Сбор и обработка материала - Александрова А. K.

Написание текста - Александрова А. К., Смольянникова В. А.

Редактирование - Смольянникова В. А.

\section{Литература/References}

1. Wolff K. L., Goldsmith A. L., Katz S. I., Gilchrest B. A., Paller A. S., Leffell D. J. Fitzpatrick's Dermatology in General Medicine. 7th ed. New York: McGraw-Hill Medical, 2007. P. 1635-1636.

2. Roh N. K., Hahn H. J., Lee Y. W., Choe Y. B., Ahn K. J. Clinical and Histopathologocal Investigation of Seborrheic Keratosis. Ann Dermatol. 2016;28(2):152-158.

3. Elder D., Elenitsas R., Johnson B., Murphy G. F., Xu X. Lever's histopathology of the skin. 10th ed. Philadelphia: Lippincott-Raven, 2009. P. 795-798.

4. Muzumdar S., Argraves M., Kristjansson A., Ferenczi K., Dadras S. S. A quantitative comparison between SOX10 and MART-1 im- munostaining to detect melanocytic hyperplasia in chronically sun-damaged skin. J Cutan Pathol. 2018;45(4):263-268.

5. Helm K., Findeis-Hosey J. Immunohistochemistry of pigmented actinic keratoses, actinic keratoses, melanomas in situ and solar lentigines with Melan-A. J Cutan Pathol. 2008;35(10):931-934.

6. Manaka L., Kadono S., Kawashima M., Kobayashi T., Imokawa $\mathrm{G}$. The mechanism of hyperpigmentation in seborrhoeic keratosis involves the high expression of endothelin-converting enzyme-1alpha and TNF-alpha, which stimulate secretion of endothelin 1. $\mathrm{Br} J$ Dermatol. 2001;145(6):895-903. 


\section{Информация об авторах}

Александра Константиновна Александрова* - к.м.н., докторант касредры патологической анатомии им. академика А. И. Струкова Первого Московского государственного медицинского университета им. И. М. Сеченова (Сеченовский университет) Министерства здравоохранения Российской Федерации; e-mail: veter278@rambler.ru; SPIN: 8736-0698; http://orcid.org/0000-0001-9166-9807

Вера Анатольевна Смольянникова - д.м.н., профессор кафедры патологической анатомии им. академика А. И. Струкова Первого Московского государственного медицинского университета им. И. М. Сеченова (Сеченовский университет) Министерства здравоохранения Российской Федерации; e-mail: smva@bk.ru; https://orcid.org/0000-0002-7759-5378

\section{Information about the authors}

Alexandra K. Alexandrova* - Cand. Sci. (Med.), Doctoral Student, Department of Pathological Anatomy named after Academician A. I. Strukov, I. M. Sechenov First Moscow State Medical University, Ministry of Health of the Russian Federation; e-mail: veter278@rambler.ru; SPIN: 8736-0698; http://orcid.org/0000-0001-9166-9807

Vera A. Smolyannikova - Dr. Sci. (Med.), Prof., Department of Pathological Anatomy named after Academician A. I. Strukov, I. M. Sechenov First Moscow State Medical University, Ministry of Health of the Russian Federation; e-mail: smva@bk.ru; https://orcid.org/0000-0002-7759-5378 